\title{
ISLAM DAN KEMAJEMUKAN DI INDONESIA \\ (Upaya Menjadikan Nilai-nilai yang Menjunjung Tinggi Kemajemukan dalam Islam sebagai Kekuatan Positif bagi Perkembangan Demokrasi)
}

\author{
Nurrohman \\ Fakultas Syari'ah dan Hukum UIN Sunan Gunung Djati Bandung \\ Email: nsyarif2006@yahoo.co.id
}

\begin{abstract}
Indonesia is a pluralistic nation when seen from diverse ethnic, cultural, linguistic, ethnic and religious diversity as a result of it is likely to have a positive impact or negative. Pluralism in Islamic thought caused by the many schools of theology, jurisprudence flow or Islamic law, schools of philosophy, mysticism or the mysticism and political currents. In this paper, the authors focus on explaining some of the factors that hinder the development of pluralism in Indonesia, which is associated with the concept of the protection of religion, the concept of 'amar ma'ruf nahyi munkar, the concept nasakh-mansukh, other threats to diversity is the rise of authoritarianism in the interpretation of religion, lack of enforcement law from law enforcement officials in Indonesia, and the weakness of education and understanding among Muslims toward religion.
\end{abstract}

\begin{abstract}
Abstrak
Indonesia merupakan bangsa yang majemuk jika dilihat dari keragaman etnis, budaya, bahasa, suku dan agama, akibat dari kemajemukan itu kemungkinan akan berdampak positif ataupun negatif. Kemajemukan dalam pemikiran Islam diwarnai dengan banyaknya aliran teologi, aliran fiqih atau hukum Islam, aliran filsafat, aliran mistik atau mistisisme dan juga aliran politik. Dalam tulisan ini, penulis akan menjelaskan beberapa faktor yang menghambat berkembangnya kemajemukan di Indonesia diantarnya, yaitu berkaitan dengan konsep perlindungan agama, konsep 'amar ma'ruf nahyi munkar, konsep nasakh-mansukh, ancaman lain terhadap kemajemukan adalah munculnya otoritarianisme dalam penafsiran agama, kurangnya penegakkan hukum dari aparat penegak hukum di Indonesia, dan lemahnya pendidikan dan pemahaman di kalangan umat Islam terhadap agama.
\end{abstract}

Kata Kunci:

Demokrasi, Islam dan Kemajemukan, Syariat Islam

\section{A. Pendahuluan}

Dilihat dari segi etnis, budaya, bahasa, suku dan agama, Indonesia memang merupakan bangsa yang majemuk. Kemajemukan ini ibarat pisau bermata dua, bisa membawa berkah dan juga bisa membawa bencana. Kapan kemajemukan bisa membawa berkah dan kapan kemajemukan bisa membawa bencana amat tergantung pada cara bangsa Indonesia menyikapi kemajemukan itu. Akan tetapi mengingat mayoritas (lebih dari 85\%) penduduk Indonesia adalah muslim, maka sikap dan cara pandang umat Islam terhadap kemajemukan menjadi sangat penting karena akan memiliki dampak yang signifikan bagi bangsa Indonesia secara keseluruhan.

Manakala umat Islam memandang kemajemukan sebagai sesuatu yang positif maka pandangan itu akan memberikan kontribusi yang penting bagi terwujudnya kema- 
jemukan yang bisa membawa rahmat. Sebaliknya bila umat Islam memandang kemajemukan sebagai suatu yang negatif maka pandangan itu berpotensi menyulut konflik. Dalam konteks ini, amat penting, bila cara pandang yang positif terhadap kemajemukan terus dipromosikan di kalangan umat Islam.

Akan tetapi upaya mempromosikan pandangan yang positif terhadap kemajemukan di Indonesia di tengah-tengah munculnya pertarungan ideology beserta gerakan politik yang menyertainya bukan sesuatu yang mudah. Ada indikasi bahwa gerakan puritanisme radikal lengkap dengan agenda politiknya juga sedang mencoba mengarahkan bangsa Indonesia ke cara beragama yang monolitik melalui sikap dan tindakannya yang tidak toleran terhadap cara pandang dan cara hidup yang berbeda dengan cara mereka.

Pada masa orde baru gerakan radikal dengan agenda politik yang berpotensi mengancam Negara pluralistic yang berdasarkan Pancasila ini akan mendapat tekanan bahkan penangkapan. Akan tetapi pada masa reformasi setelah tumbangnya rezim autoritarian orde baru, gerakan radikal yang secara langsung atau tidak langsung mau menggantikan idelogi Pancasila dengan negara syariat atau negara Islam bisa disaksikan di berbagai daerah. ${ }^{1}$

Celakanya negara tidak bisa berbuat banyak untuk menekan kelompok-kelompok ini sebab dalam negara yang demokratis di mana hak-hak warga negara untuk berkumpul, berekspresi dan berpendapat dijamin oleh undang-undang , seradikal apapun pandangan seseorang atau keompok orang mesti diberi ruang untuk diekspresikan.

Apabila propaganda politik gerakan Islam radikal tidak di counter dengan propaganda lain yang berusaha mengedepankan nilai-nilai demokrasi, toleransi dan hak

\footnotetext{
Salah satunya adalah kelompok Jl (Jamaah Islamiyah). Untuk mengetahui lebih lanjut bisa dibaca buku tulisan mantan salah satu pimpinan JI, Nasir Abas yang berjudul: Membongkar Jamaah Islamiyah.
}

asasi manusia, maka mereka semakin leluasa untuk mengklaim diri mereka sebagai kelompok yang mewakili "kebenaran Islam". Untuk itu diskusi dan seminar yang berbicara tentang kemajemukan dalam Islam, kemajemukan di Indonesia disertai dengan upayaupaya menjadikan kemajemukan sebagai kekuatan yang positif bagi perkembangan demokrasi di Indonesia menjadi sesuatu yang amat penting.

Indonesia adalah Negara Islam terbesar di dunia. Indonesia juga merupakan negara demokrasi terbesar ketiga setelah Amerika Serikat dan India. Oleh karena itu, jika kemajemukan dalam Islam dan kemajemukan dalam masyarakat Indonesia tidak bisa dikelola menjadi kekuatan yang positif maka akan melahirkan citra negatif bagi Islam dan citra negatif bagi demokrasi di Indonesia.

Tulisan ini akan membahas tentang kemajemukan dalam Islam, faktor-faktor yang bisa menghambat berkembangnya paham kemajemukan dalam Islam, serta mendiskusikan bagaimana menjadikan kemajemukan itu menjadi sesuatu yang positif bagi konsolidasi demokrasi di Indonesia.

\section{B. Kemajemukan dalam Islam}

\section{Kemajemukan dalam al-Quran}

Al-Quran mengingatkan bahwa adanya perbedaan-perbedaan di antara umat manusia agar manusia saling mengenal dan saling menghormati. ${ }^{2}$

Dalam menyikapi perbedaan agama alQuran dengan jelas memberikan petunjuk agar manusia menganut prinsip bagimu agamamu dan bagiju agamaku. ${ }^{3}$ Dalam urusan agama manusia tidak bisa dipaksa. ${ }^{4} \mathrm{Nabi}$ Muhammad sendiri tidak diperkenankan untuk memaksa orang lain menjadi mukmin. ${ }^{5}$ Al-Quran juga menginformasikan kepada umat Islam tentang kemungkinan adanya keselamatan yang bisa diperoleh lewat agama lain. Keselamatan mungkin bisa diper-

\footnotetext{
QS. al-Hujurât ayat 13 .

QS. al-Kâfirûn ayat 6.

QS. al-Baqarah ayat 256.

QS. Yûnus ayat 99.
} 
oleh umat manusia yang memenuhi tiga kriteria; iman kepada Tuhan, iman kepada hari kiamat atau hari pembalasan dan mengerjakan amalan-amalan yang baik atau amal shaleh. ${ }^{6}$ Oleh karena itu, al-Quran juga memberikan bimbingan agar perbedaan keyakinan dalam agama sebaiknya diserahkan kepada Tuhan jangan dihakimi oleh manusia di dunia ini. ${ }^{7}$ Biarkan mereka masing-masing memiliki kebanggaan dengan golongannya sendiri. ${ }^{8}$ Oleh karena itu, al-Quran mengajarkan agar kaum beriman hendaknya tidak memberikan penghinaan atau stigma negatif terhadap kelompok lain. ${ }^{9}$

\section{Kemajemukan yang Dipraktikkan Nabi Muhammad dalam Piagam Madinah}

Kemajemukan dalam kehidupan sosial dicontohkan oleh Nabi Muhammad pada saat beliau dipercaya untuk memimpin masyarakat Madinah. Masyarakat Madinah adalah masyarakat yang plural. Mereka terdiri atas berbagai suku dan agama. Oleh karena itu, kehidupan di Madinah dibangun atas dasar konsensus yang kemudian dituangkan dalam 'konstitusi' yang kemudian dikenal dengan sebutan Piagam Madinah. Dalam Piagam Madinah ini disebutkan bahwa semua pemeluk Islam, meskipun berasal dari banyak suku, tetapi merupakan satu komunitas. Hubungan antara sesama anggota komunitas Islam dengan anggota komunitas-komunitas lain didasarkan atas prinsip-prinsip: (a) bertetangga baik; (b) saling membantu dalam menghadapi musuh bersama; (c) membela mereka yang teraniaya; (d) saling menasihati; dan (e) menghormati kebebasan beragama. Satu hal yang patut dicatat bahwa Piagam Madinah yang oleh banyak pakar

6 QS. al-Baqarah ayat 62.

QS. al-An'âm ayat 159. Artinya: Sesungguhnya orang-orang yang memecah belah agamanya dan mereka menjadi bergolongan, tidak ada sedikitpun tanggung jawabmu terhadap mereka. Sesungguhnya urusan mereka hanyalah (terserah) kepada Allah, kemudian Allah akan memberitahukan kepada mereka apa yang telah meraka perbuat.

8 QS. al-Rûm ayat 32.

9 QS. al-Hujurât ayat 11. politik didakwakan sebagai konstitusi Negara Islam yang pertama itu tidak menyebut agama Negara. ${ }^{10}$ Piagam Madinah juga memberikan hak yang setara terhadap warga negara muslim dan non-muslim, mereka sama-sama terikat untuk mempertahankan dan membela negara.

\section{Kemajemukan dalam Pemikiran Islam dan Politik Islam}

Kemajemukan dalam pemikiran Islam diwarnai dengan banyaknya aliran teologi, aliran fiqih atau hukum Islam, aliran filsafat, aliran mistik atau mistisisme dan juga aliran politik. Banyaknya aliran pemikiran yang muncul dalam Islam, di samping karena Nabi mendorong umat Islam untuk terus berijtihad untuk menangkap apa yang terkandung dalam pesan kitab suci agar senantiasa relevan dengan perkembangan zaman, juga karena Nabi sendiri memandang positif terhadap perebedaan pendapat. Perbedaan pendapat di kalangan umatku akan membawa rahmat, kata Nabi.

Berkenaan dengan politik Islam, sungguhpun para ulama umumnya sepakat bahwa umat Islam mesti terikat dengan normanorma yang terkandung dalam syariat, tetapi sejak awal para ulama tidak sepakat dalam mewajibkan pendirian negara atau pemerintahan Islam. Perbedaan itu bertolak dari pertanyaan apakah dalam melaksanakan norma-norma syariat, umat Islam tergantung pada wujudnya Negara atau pemerintahan Islam? Mereka yang yakin bahwa syariat Islam tidak bisa dijalankan tanpa adanya Negara akan berpendapat bahwa mendirikan Negara wajib. Mereka yang merasa bahwa syariat Islam bisa dilaksanakan tanpa adanya negara, berpendapat bahwa mendirikan negara tidak wajib. Umat Islam bisa menjalankan syariat agamanya di negara mana saja, selama Negara itu memberikan perlindungan bagi warganya untuk mengekspresikan keyakinan agamanya. Sebagai nor-

10 Munawir Sjadzali, Islam dan Tata Negara (Jakarta: UI-Press. 1990), hlm. 16. 
ma agama yang dijalankan atas dasar keyakinan dan kesadaran, syariat Islam bisa jalan tanpa perlu adanya kekuatan luar atau paksaan dari negara.

Perdebatan tentang hubungan antara syariat Islam dengan Negara ini terus berlangsung sampai umat Islam memasuki periode modern. Itulah sebabmya, pada saat memasuki periode modern, dimana Negaranegara muslim mulai melepaskan diri dari kolonialisme dan berusaha membentuk negara modern berdasarkan konstitusi tertulis, muncul banyak ragam dalam menempatkan syariat Islam dalam konstitusi mereka. ${ }^{11}$ Setidaknya keragaman itu muncul karena dua hal. Pertama adanya perbedaan pandangan umat Islam dalam melihat hubungan agama dan Negara, kedua karena adanya perbedaan pandangan mereka dalam merumuskan apa yang disebut sebagai negara Islam (dâr al-Islâm). Tentang hubungan agama dan negara, umat Islam ada yang melihatnya sebagai hubungan yang integratif, symbiotik, separatis atau sekularis. Tentang dâr al-Islâm, terdapat beberapa rumusan, ada yang merumuskannya sebagai negara yang memberikan jaminan bagi pelaksanaan syariat Islam, ada yang merumuskannya sebagai Negara

11 Posisi Islam dan syariatnya dalam konstitusi sejumlah negara muslim bisa dibagi menjadi empat: 1) negara yang konstitusinya mengakui Islam sebagai agama negara dan menjadikan syariat Islam sebagai sumber utama pembuatan undang-undang. Di sini bisa dimasukkan Negara seperti Saudi Arabia, Libia, Pakistan, Iran dan Mesir; 2) negara yang konstitusinya menyatakan Islam sebagai agama negara tetapi tidak menyebutkan syariat Islam sebagai sumber utama pembuatan hukum artinya syariat islam hanya dipandang sebagai salah satu sumber dari beberapa sumber pembuatan hukum contohnya Irak dan Malaysia; 3) negara yang tidak menjadikan Islam sebagai agama negara dan tidak menjadikan syariat islam sebagai sumber utama pembuatan hukum tapi mengakui syariat Islam sebagai hukum yang hidup di masyarakat, contohnya Indonesia; 4) negara yang menyatakan diri sebagai negara sekuler dan berusaha agar syariat Islam tidak mempengaruhi system hukumnya, contohnya Turki. Lihat Nurrohman, Syariat Islam, Konstitusi dan hak Asasi Manusia; Studi Terhadap Pandangan Sejumlah Tokoh tentang Model Palaksanaan Syariat Islam di Daerah Istimewa Aceh, laporan penelitian, Lembaga Penelitian IAIN SGD Bandung Tahun 2002, hlm. 17. yang dipimpin oleh orang Islam, ada yang merumuskannya sebagai negara yang mayoritas penduduknya memeluk agama Islam. ${ }^{12}$ Oleh karena itu, menurut penulis, tidak benar bila dalam wacana pemikiran politik, Islam dibenturkan dengan sekularisme. Yang benar adalah bahwa umat Islam memiliki banyak wajah dalam pemikiran politik dan kenyataan politik. ${ }^{13}$

\section{Faktor-faktor yang Bisa Menghambat Berkembangnya Kemajemukan di Indo- nesia}

Mengapa sebagian kaum muslim masih sulit menerima kemajemukan? Menurut penulis ada beberapa faktor yang menjadikan sebagian muslim sulit menerima kemajemukan dan toleransi.

Pertama, berkaitan dengan konsep perlindungan agama (hifzh al-dîn) dalam hukum Islam. Konsep ini mestinya digunakan untuk melindungi semua penganut agama, melindungi orang yang melaksanakan keyakinan dan kewajiban agamanya. Mengapa? Karena al-Quran jelas memberikan jaminan bahwa tidak boleh ada paksaan dalam agama, bagimu agamamu dan bagiku agamaku lâ ikrahâ fî al-dîn dan lakum dînukum wa liya dîn. Tetapi sebagian ulama masih memegang pandangan bahwa orang pindah agama dari agama Islam ke agama lain atau orang yang menghina agama Islam maka harus dinilai sebagai orang murtad dan hukuman untuk orang murtad menurut fiqih klasik adalah dibunuh.

Oleh karena itu, bisa dimengerti bila setelah adanya fatwa yang menyatakan bahwa jamaah Ahmadiyah adalah sekte yang sesat dan pengkutnya adalah murtad ada penganut garis keras yang menyatakan bahwa darah anggota jamaah Ahmadiyah halal.

12 Lihat, Nurrohman, "Islamic state campaigners need syariah interpretation" dalam The Jakarta Post, May 11 Tahun 2002.

13 Penulis setuju dengan istilah Many Faces of Political Islam, yang akan dijadikan Mohammed Ayoob, guru besar hubungan internasional dari Universitas Michigan, sebagai judul bukunya. 
Kedua, berkaitan dengan konsep 'amar ma'ruf nahyi munkar yang diambil dari hadits nabi yang berbunyi man ra'a minkum munkaran fal yugayyir biyadîh. (Barangsiapa melihat kemungkaran, maka rubahlah dengan tangan atau kekuasaannya). Sayangnya kelompok muslim garis keras sering menerjemahkan atau menggantikan kata falyugayyir (merubah) dengan falyudammir (menghancurkan). Harus diakui bahwa merubah lebih sulit dari menghancurkan. Merubah tanpa menghancurkan membutuhkan lebih banyak kerja keras dan kesabaran. Itu juga membutuhkan studi yang lebih dalam tentang faktor-faktor yang mempengaruhi serta hubungan antara satu faktor dengan faktor lainnya. Contoh, ketika kelompok garis keras siap untuk menghancurkan prostitusi di kawasan Saritem, KH. Imam Sonhaji, pimpinan Syuriah NU kota Bandung misalnya lebih memilih mendirikan pesantren Dâr alTawbah di lokasi itu dan melakukan pendekatan secara bijaksana (bil hikmah) kepada mereka ketimbang melakukan perusakan atau pembakaran. Kalaupun mau ditutup penutupan harus dengan cara yang bijaksana dengan mempertimbangkan aspirasi dari pihak-pihak yang menjadi “korban'.

Ketiga, adalah konsep nasakh-mansukh. Konsep ini didasarkan atas asumsi bahwa banyak ayat al-Quran yang satu sama lain saling bertentangan. Untuk mengatasi hal ini dibuatlah konsep nasakh-mansukh yang menyatakan bahwa ayat-ayat yang diturunkan terlebih dahulu bisa di nasakh (dihapus) oleh ayat-ayat yang turun belakangan. Padahal alQuran sendiri mendorong umat Islam untuk melakukan penalaran yang mendalam terhadap al-Quran (tadabbur). ${ }^{14}$ Jika seseorang bersedia melakukan studi yang mendalam terhadap al-Quran dengan melihat konteks sosial dan asbâb al-nuzûl-nya maka ia bisa menemukan bahwa sebenarnya tidak ada kontradiksi dalam kitab suci ini.

Irfan A. Omar, professor di bidang agama dari Universitas Marquette, Milwau-

14 QS. al-Nisâ' ayat 82. ke, USA menyatakan bahwa penghormatan al-Quran terhadap berbagai agama didasarkan atas gagasannya kesatuan kitab suci. Dia menyatakan bahwa semua wahyu datang dari sumber yang suci yakni lawhi mahfûzh (all revelations came from the divine source, the 'well-guarded tablet' or lawhi mahfûzh). Oleh karena itu, menurutnya bisa disimpulkan bahwa al-Quran sebenarnya menerima kemajemukan (pluralitas) agama. Karena alQuran sebenarnya hanya menuntut dua hal agar seseorang bisa disebut beriman 1) iman kepada Tuhan dan hari akhir; dan 2) mengerjakan amal shaleh. Al-Quran surat al-Baqarah ayat 62 dan surat al-Mâidah ayat 69 amat jelas menyebut bahwa orang lain yang boleh jadi bukan Muslim (penganut agama Islam) mungkin memiliki keimanan dan boleh jadi diselamatkan nanti pada hari kiamat. Muhammad Asad dalam tafsirnya terhadap ayat-ayat ini bahwa the idea of "salvation" here made conditional upon three elements only: belief in God, belief in the Day of Judgment, and righteous action in life. ${ }^{15}$

Sayangnya ayat-ayat al-Quran yang mendorong kemajemukan, oleh sebagian ulama dipandang sebagai ayat yang sudah di nasakh. Menganggap bahwa ayat-ayat yang memperkuat kemajemukan dan toleransi sebagai ayat yang sudah di nasakh sama artinya dengan mengabaikan bagian dari ayat-ayat al-Quran yang bisa digunakan sebagai proposisi untuk mengembangkan kemajemukan dan toleransi.

Keempat, ancaman lain terhadap kemajemukan adalah munculnya otoritarianisme dalam penafsiran agama. ${ }^{16}$ Kelompok ini,

15 Dikutip dari makalah yang disampaikan oleh Irfan A. Omar, dalam diskusi yang bertema: "Islam, pluralisme and religious tolerance" yang diselenggarakan oleh Program Pasca Sarjana UIN Bandung pada tanggal 18 Mei 2006. Rasyid Ridlâ dalam bukunya Wahyû al-Muhammadî juga memiliki pandangan yang sama, beliau menyebutnya sebagai rukun agama.

16 Khaled Abou el-Fadl dalam bukunya Speaking in God's name, Islamic Law, Authority and Women (2003) mengatakan: "Authoritarianism is the act of locking or captivating the will of Divine or the will of the text into the specific determination as inevitable, 
meskipun terkadang hanya sekelompok kecil, berpotensi merusak tatanan masyarakat yang plural karena berusaha memaksakan pendapatnya terhadap kelompok lain dengan berbagai cara termasuk dengan caracara kekerasan. Kelompok ini seolah-olah mengklaim bahwa dirinya saja yang berhak mewakili Tuhan, dirinya saja yang selamat dan yang akan masuk sorga sementara yang lain sesat dan akan masuk neraka. Otoritarianisme dalam penafsiran agama bisa menguat manakala mendapat dukungan penguasa atau para pimpinan lembaga agama.

Kelima, kurangnya penegakkan hukum dari aparat penegak hukum di Indonesia. Dalam banyak kasus jurtru bukan penyerang yang ditangkap dan diperiksa oleh polisi tapi malah korbannya. Adalah hak MUI (Majelis Ulama Indonesia) untuk mengeluarkan fatwa yang menyatakan bahwa ajaran agama yang dipengaruhi oleh pluralisme, liberalisme dan sekularisme adalah bertentangan dengan Islam. Adalah hak MUI untuk mengatakan bahwa Muslim mesti mempertimbangkan agama mereka sebagai agama yang benar dan mempertimbangkan keyakinan lain sebagai keyakinan yang keliru. Dalam Negara demokrasi orang boleh berpendapat bahwa jamaah Ahmadiyah, kelompok Islam yang tidak mengakui nabi Muhammad sebagai nabi terakhir, sesat dan pengikutnya bisa dinilai murtad. Tetapi pada saat kelompok garis keras menggunakan fatwa ini untuk menyerang jamaah Ahmadiyah secara fisik atau melakukan perusakan, adalah kewajiban polisi untuk mencegah atau menghalanginya.

Keenam, lemahnya pendidikan dan pemahaman di kalangan umat Islam terhadap agamanya sendiri. Penulis setuju dengan penilaian Zulkiflimansyah wakil ketua fraksi PKS (Partai Keadilan Sejahtera) di DPR saat diwawancarai oleh Pieter F. Gontha di sebuah stasiun televisi swasta beberapa waktu yang lalu. Dia menyatakan bahwa faktor utama

final and conclusive" dikutip dari M. Hilaly Basya, Radicalism and Authoritarianism, The Jakarta Post, Januari 30 Tahun 2006. menjadikan munculnya intolerance dan fundamentalisme di Indonesia adalah lemahnya pendidikan umat Islam sebagai akibat dari kemiskinan. Harus diakui bahwa kekerasan dalam agama dalam banyak kasus seringkali ada hubungannya dengan konflik politik atau kepentingan politik. Sejumlah orang menggunakan symbol-simbol agama sebagai komoditi politik untuk memperoleh kekuasaan tetapi sebenarnya mempolitisir agama akan lebih sulit bila umat Islam di Indonesia semakin pandai dan semakin sejahtera.

Dalam konteks Indonesia yang sedang melakukan konsolidasi demokrasi, kekhawatiran akan munculnya kekuatan yang bisa menekan kemajemukan masih mungkin terjadi. Demokrasi bisa mengarah kepada tirani mayoritas manakala demokrasi dipahami semata-mata sebagai demokrasi prosedural di mana suara mayoritas yang menjadi tolok ukur demokrasi digunakan untuk menekan kebebasan sipil termasuk kebebasan dalam beragama. Demokrasi menjadi positif bila dimaknai sebagai upaya untuk mengembalikan kedaulatan kepada rakyat dalam memilih pemimpinnya. Demokrasi juga positif sebagai upaya untuk melibatkan partisipasi masyarakat dalam mengurus persoalan public. Akan tetapi demokrasi bisa negatif bila digunakan oleh mayoritas untuk mengatur secara paksa cara hidup (way of life) kelompok marginal atau minoritas. Yang terakhir ini bisa berakibat dilanggarnya hak-hak asasi kaum minoritas atau kelompok marginal. Kalau ini terjadi maka yang muncul adalah apa yang disebut oleh Fareed Zakaria sebagai illiberal form of society yakni pada saat masyarakat diperintah oleh seorang dictator yang mengabaikan atau melanggar hak asasi manusia.$^{17}$ Dalam kaitan ini , munculnya kekhawatiran dari sekelompok orang terhadap sejumlah Peraturan Daerah yang diilhami oleh hukum Islam bisa dimengerti karena beberapa bagian dari aturan itu berpotensi me-

17 Sunny Tanuwidjaja, Islamic bylaws and democracy, dalam The Jakarta Post, July 1 Tahun 2006. 
nimbulkan diskriminasi dan melanggar hak asasi manusia.

\section{Penutup}

Semua keterangan di atas menunjukkan bahwa upaya menjadikan nilai-nilai kemajemukan dalam Islam sebagai kekuatan yang mendorong demokrasi dan civil society memerlukan beberapa pembenahan dan perubahan. Pertama pembenahan dari sisi pandangan teologis. Perubahan pandangan teologis akan merubah mind set atau cara berpikir seseorang. Umat Islam mesti didorong untuk berani berpikir secara kritis atau berijtihad sembari berusaha menghilangkan autoritarianisme dalam penafsiran keagamaan. Kritik dan koreksi terhadap ketentuanketentuan lama yang sudah tidak relevan dengan perkembangan zaman mesti dinilai sebagai sesuatu yang positif. Karena "kebenaran" yang di dapat oleh manusia harus senantiasa terbuka terhadap proses verifikasi (verification) atau falsifikasi (falsification).

Kemudian meskipun agama tidak bisa dipisahkan sama sekali dari politik, mengingat agama juga peduli terhadap problemproblem sosial kemasyarakatan bahkan agama bisa kehilangan maknanya bila tidak bisa hadir di tengah-tengah umat yang tertindas dan menrderita , tapi politisasi agama dalam pengertian menggunakan symbol-simbol agama sebagai justifikasi kepentingan politik harus sama-sama dihindari.

Umat Islam hendaknya terus belajar menyelesaikan perbedaan pendapat dengan cara-cara yang lebih beradab melalui dialog atau tukar pikiran. Sebab melalui dialog dan tukar pikiran bisa ditemukan akar masalah yang lebih substantive dan tidak jarang bahwa masalah-maslah yang berbeda secara lahiriyah kalau didalami memiliki substansi yang sama. Bila perbedaan pendapat atau konflik tidak bisa dihindari maka penyelesaian konflik berdasarkan hukum yang berlaku tentu lebih beradab dibanding penyelesaian konflik melalui mob atau tekanan masa.
Bangsa Indonesia, khususnya umat Islam perlu mendorong tumbuhnya demokrasi yang sehat dimana kebebasan berpendapat, berekspresi benar-benar dijamin dan tidak ada diskriminasi berdasarkan agama, etnis maupun golongan, bukan semata-mata demokrasi procedural. Karena demokrasi bila dipahami hanya sekedar prosedur maka bisa melahirkan apa yang disebut diktator mayoritas dan tirani minoritas. Demokrasi memang tidak serta merta membawa keadilan dan kesejahteraan, tetapi sebagai bentuk pemerintahan, demokrasi memang lebih baik ketimbang yang lain.

\section{Daftar Pustaka}

Abas, Nasir. 2006. Membongkar Jamaah Islamiyah. Jakarta: Grafindo.

Basya, M. Hilaly. 2006. "Radicalism and Authoritarianism". Dalam The Jakarta Post. Januari 30 Tahun 2006.

Honoris, Charles. 2006. "Democracy at the crossroad in Indonesia after 61 years". dalam The Jakarta Post. September 15 Tahun 2006.

Nurrohman. 2002. "Islamic state campaignners need syariat interpretation". dalam The Jakarta Post. Mai 11 Tahun 2002.

Nurrohman. 2002. "Syariat Islam, Konstitusi dan Hak Asasi Manusia; Studi Terhadap Pandangan Sejumlah Tokoh tentang Model Palaksanaan Syariat Islam di Daerah Istimewa Aceh. dalam laporan penelitian. Bandung: Lembaga Penelitian IAIN SGD Bandung.

Nurrohman. 2007. "Questioning theocratic caliphate". Dalam The Jakarta Post. Agustus 24 Tahun 2007.

Omar, Irfan A. 2006. "Pluralisme dalam Islam". makalah disampaikan dalam diskusi yang bertema: "Islam, pluralism and religious tolerance" yang diselenggarakan oleh Program Pasca Sarjana UIN Bandung pada tanggal 18 Mei 2006.

Ridlâ, Rasyid. t.th. Wahyu al-Muhammadî. Mesir: t.pn. 
Sjadzali, Munawir. 1990. Islam dan Tata Negara. Jakarta: UI-Press.
Tanuwidjaja, Sunny. 2006. "Islamic bylaws and democracy". dalam The Jakarta Post. July 12006. 